\title{
Prehospital time of suspected stroke patients treated by emergency medical service: a nationwide study in Thailand
}

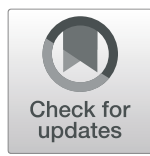

Phantakan Tansuwannarat ${ }^{1}$, Pongsakorn Atiksawedparit ${ }^{1 *} \mathbb{D}$, Arrug Wibulpolprasert ${ }^{2}$ and Natdanai Mankasetkit $^{1}$

\begin{abstract}
Background: This work was to study the prehospital time among suspected stroke patients who were transported by an emergency medical service (EMS) system using a national database.

Methods: National EMS database of suspected stroke patients who were treated by EMS system across 77 provinces of Thailand between January 1, 2015, and December 31, 2018, was retrospectively analyzed. Demographic data (i.e., regions, shifts, levels of ambulance, and distance to the scene) and prehospital time (i.e., dispatch, activation, response, scene, and transportation time) were extracted. Time parameters were also categorized according to the guidelines.

Results: Total 53,536 subjects were included in the analysis. Most of the subjects were transported during 06.0018.00 (77.5\%) and were $10 \mathrm{~km}$ from the ambulance parking (80.2\%). Half of the subjects (50.1\%) were served by advanced life support (ALS) ambulance. Median total time was 29 min (IQR 21, 39). There was a significant difference of median total time among ALS (30 min), basic (27 min), and first responder (28 min) ambulances, Holm $P=0.009$. Although $91.7 \%$ and $88.3 \%$ of the subjects had dispatch time $\leq 1 \mathrm{~min}$ and activation time $\leq 2 \mathrm{~min}$, only $48.3 \%$ had RT $\leq 8 \mathrm{~min}$. However, $95 \%$ of the services were at the scene $\leq 15 \mathrm{~min}$.

Conclusion: Prehospital time from EMS call to hospital was approximately 30 min which was mainly utilized for traveling from the ambulance parking to the scene and transporting patients from the scene to hospitals. Even though only $48 \%$ of the services had RT $\leq 8 \mathrm{~min}, 95 \%$ of them had the scene time $\leq 15 \mathrm{~min}$.
\end{abstract}

Keywords: Stroke, EMS, Ambulance, Prehospital care, Response time, Thailand

\section{Background}

Cerebrovascular accident (stroke) is a time-sensitive condition in which blood vessel infarction or hemorrhage causes some disorders to brain function. This is the leading cause of deaths and disabilities worldwide [1]. The prevalence of stroke and stroke-related deaths ranges from 60 to 700 per 100,000 population and from 22.4 to 263.9 per 100,000 population,

\footnotetext{
*Correspondence: pongsakorn.ati@mahidol.edu; kawhommali@hotmail.com ${ }^{1}$ Chakri Naruebodindra Medical Institute, Faculty of Medicine Ramathibodi Hospital, Mahidol University, Samut Prakan 10540, Thailand

Full list of author information is available at the end of the article
}

respectively $[1,2]$. To reduce the magnitude of deaths and disabilities, stroke chain of survival has been introduced which includes an early recognition of signs/ symptoms of stroke, an activation of emergency medical service (EMS) with timely response, transport to stroke center with pre-arrival notification, and an implementation of guidelines on stroke care with high quality poststroke rehabilitation [3,4]. Currently, several pieces of evidence indicate applying EMS system to the stroke care process can improve quality of management and decrease prehospital delays [5-7]. Therefore, the American Heart Association and the American Stroke

(c) The Author(s). 2021 Open Access This article is licensed under a Creative Commons Attribution 4.0 International License, which permits use, sharing, adaptation, distribution and reproduction in any medium or format, as long as you give appropriate credit to the original author(s) and the source, provide a link to the Creative Commons licence, and indicate if changes were made. The images or other third party material in this article are included in the article's Creative Commons licence, unless indicated otherwise in a credit line to the material. If material is not included in the article's Creative Commons licence and your intended use is not permitted by statutory regulation or exceeds the permitted use, you will need to obtain permission directly from the copyright holder. To view a copy of this licence, visit http://creativecommons.org/licenses/by/4.0/ The Creative Commons Public Domain Dedication waiver (http://creativecommons.org/publicdomain/zero/1.0/) applies to the data made available in this article, unless otherwise stated in a credit line to the data. 
Association (AHA/ASA) have introduced specific parameters to measure the quality of EMS care for stroke patients which include the highest level of care available for suspected stroke patients: dispatch time $\leq 60 \mathrm{~s}$, activation time $\leq 60 \mathrm{~s}$, response time $(\mathrm{RT}) \leq 8 \mathrm{~m}$, and on-scene time $\leq 15 \mathrm{~m}[8,9]$. In addition, previous studies in several countries, where EMS system is well developed, reported a high percentage (47 to $72 \%$ ) of stroke patients who were transferred to the hospitals by ambulance [10-12].

In Thailand, the prevalence of stroke is 122 per 100,000 population [13] and this rate in 45 years old or older people contributes $1.88 \%$ [14]. This has also been one of the top three causes of burden of disease among Thai population [15]. Stroke fast track protocol has been widely implemented among emergency departments (ED) in Thailand. However, combining EMS system with this protocol has not been systematically initiated because the EMS system is still under the developing stage. Furthermore, previous studies in Thailand reported 5.5 to $20.5 \%$ of stroke patients visiting ED by EMS system [16-19]. To identify the strategy for developing EMS stroke fast track, the current performance of EMS on suspected stroke patients should be determined. Hence, we aimed to study the prehospital specific parameters among suspected stroke patients who were transported by EMS system based on the national database.

\section{Methods}

\section{Study design}

We conducted a nationwide cross-sectional study among suspected stroke patients transported to hospitals by EMS system in Thailand between January 1, 2015, and December 31, 2018. This study was approved by the Ethic Committee of the Faculty of Medicine, Ramathibodi Hospital, Mahidol University, Thailand, with a waiving of informed consent.

\section{Study setting and population}

In 2019, there were approximately 66.5 million people [20] living in the capital city, Bangkok, and 76 provinces. These 76 provinces are divided into six regions according to the geography (i.e., the north, north-east, middle, east, west, and south), see Fig. 1A [21]. Each province is divided into districts and there are provincial and district-based hospitals.

For a decade, a multi-tiered ground EMS system in Thailand has been established to cover prehospital care. Dispatch centers are located at provincial hospitals. The levels of ambulance are divided into advanced life support (ALS), intermediate life support (ILS), basic life support (BLS), and first responder (FR). ALS ambulances are a fixed deploying model and they are parked at provincial and district hospitals, whereas BLS and FR are fluid deploying models. Dispatch center categorizes chief complaints of all emergency calls regarding 25 criteria- based dispatch. Subsequently, the severity of chief complaints is prioritized to dispatch appropriate levels of ambulance, see Additional file 1 [22]. Emergency level of phone triage is assigned to patients if the gathered information suggests alteration of consciousness, airway obstruction, severe respiratory distress, or shock. For other less severe conditions, urgency level is assigned. In case ALS ambulance is not available, the highest ambulance available is dispatched. Generally, patients are sent to the nearest hospital after prehospital treatment. The information gained during prehospital operation has to be uploaded to the national database via the Information Technology for Emergency Medical System which is managed by the National Institute for Emergency Medicine of the Ministry of Public Health. This study enrolled all suspected stroke adult patients who met criteria-based dispatch code 18: paralysis, weakness, loss of sensation, dysarthria, or facial palsy (ischemic or hemorrhagic stroke), and were transported to hospitals by EMS system from January 1, 2015, to December 31, 2018. We excluded patients whose time variables were missing.

\section{Variables and data collection}

All data were retrieved from the Information Technology for Emergency Medical System database. Duplicated records were explored and excluded. Data were cleaned and checked for correctness before the final analysis. The primary outcome was prehospital time intervals (i.e., dispatch, activation, response, scene, and transportation time). The definitions of prehospital time were described in Fig. 2. Dispatch triage was prioritized as emergency and urgency levels.

\section{Statistical analysis}

A complete case analysis was applied. Continuous and categorical data were displayed as median (interquartile range: IQR) and number (\%), respectively. According to cut off point of national key performance indicator (KPI), dispatch time, activation time, RT, and distance from EMS base to the scene were categorized to $\leq 1$ versus $>1 \mathrm{~min}, \leq 2$ versus $>2 \mathrm{~min}, \leq 8$ versus $>8 \mathrm{~min}$, and $\leq 10$ versus $>10 \mathrm{~km}$, respectively [23]. In contrast, the scene time was categorized as $\leq 15$ versus $>15 \mathrm{~min}$ based on AHA/ASA 2007 and 2013 recommendations [8, 9]. The Chi-square test was used to compare the difference among categorical data. For continuous data, the test for normality was performed prior to subsequent analysis. Linear regression or quantile regression was used to compare more than two groups of normal distributed and non-normal distributed continuous data, respectively. An adjustment for multiple hypothesis testing was applied by estimating the family-wise error rate (Holm $P$ value) by using the Holm-Bonferroni correction [24]. Statistical significance was considered if Holm $P$ value < 


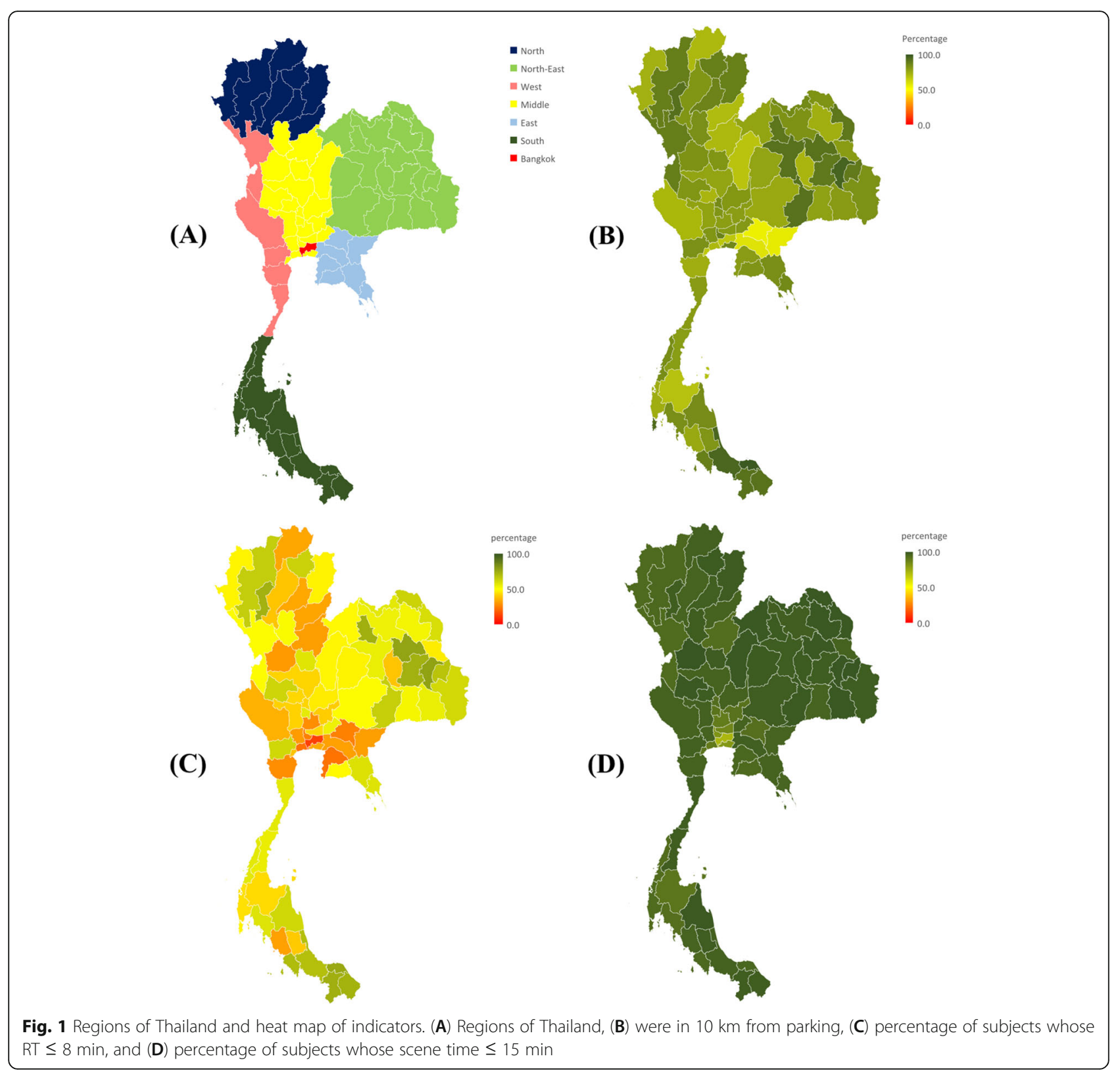

Total prehospital time

Response time

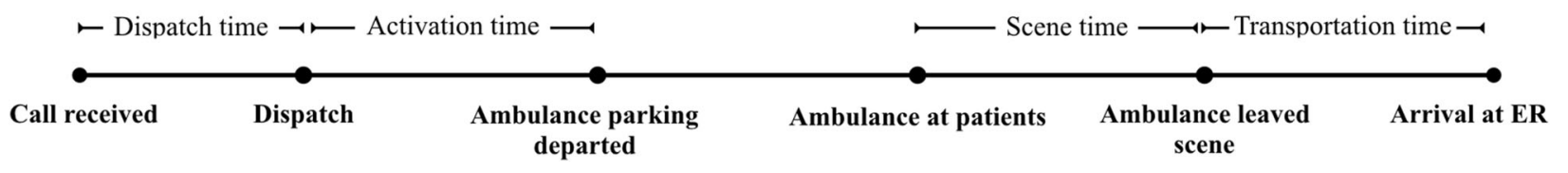

Fig. 2 Definition of EMS operation times 
0.05. All analyses were conducted using STATA version 15.0 (Stata Corp., College Station, TX, USA), except for map charts which were constructed by Microsoft Excel (2019).

\section{Results}

During the study period, there were 55,372 suspected stroke subjects transported to the emergency room by ambulance. Of those, 1836 (3.3\%) subjects were excluded due to incomplete information. Therefore, 53,536 subjects were included in the final analysis.

\section{Characteristics of EMS operation}

Most of the subjects were in the north-eastern region (38.9\%). Approximately, $77.5 \%$ of the subjects were transported during 06.00-18.00. Only half of the subjects were served by ALS ambulances (50.1\%) and prioritized as emergency level (52.2\%). There were $80.2 \%$ of the subjects who were within $10 \mathrm{~km}$ from the ambulance parking. The characteristics of subjects from 2015 to 2018 were consistent, see Table 1.

Table 2 described the number (\%) of the subjects who were $\leq 10$ versus $>10 \mathrm{~km}$ from the ambulance parking. The results indicated the percentage ranged from 70 to $84.7 \%$ across six regions, whereas only $66.3 \%$ was found in Bangkok. There was a significantly different percentage of the subjects who were $10 \mathrm{~km}$ away from the ambulance parking with FR, BLS, and ALS ambulances contributing $90.4 \%, 83 \%$, and $72.3 \%$, respectively (Holm $P=0.039$ ).

The characteristics of EMS operation (i.e., phone triage and levels of ambulance) among six regions and Bangkok were different (Holm $P=0.009$ and 0.019, respectively), see Table 3 . The percentage of the subjects who were prioritized as emergency level ranged from 33.3 to $85.1 \%$. The higher percentage of emergency cases and the higher percentage of ALS ambulances were deployed. Additionally, there was no FR ambulance dispatched to subjects in Bangkok.

\section{EMS operation times}

EMS operation time was described in Table 4. Median total prehospital time among enrolled subjects was 29 min (IQR 21, 39). The longest total time was found in an advanced level with median $30 \mathrm{~min}$ (Holm $P=$ $0.014)$. Most of the total time was occupied by transportation time (median $10 \mathrm{~min}$ with IQR 6, 17), response time (median 9 min with IQR 5, 14), and scene time (median 5 min with IQR 2, 8), respectively. Median response time of FR was significantly shorter than that of ILS/BLS and ALS ambulances (6 min versus 8 and 11 min, respectively; Holm $P=0.029$ ). However, median scene time of FR (3 min) was also shorter than that of ILS/BLS and ALS ambulances (4 and 5 min, respectively;
Holm $P=0.024)$, but median transportation time was longer (14 min versus 10 and 9 min, respectively; Holm $P=0.019)$.

There were $91.7 \%$ and $88.3 \%$ of the operations had dispatch time in $1 \mathrm{~min}$ and activation time in $2 \mathrm{~min}$, respectively. Despite this, only $48.3 \%$ of the operations had $\mathrm{RT} \leq 8 \mathrm{~min}$. However, most of the operations (95\%) were at the scene in less than $15 \mathrm{~min}$. The lowest percentage of dispatch time $\leq 1 \mathrm{~min}(88.8 \%)$, activation time $\leq 2 \mathrm{~min}(83.5 \%)$, response time $\leq 8 \mathrm{~min}(33.9 \%)$, and scene time $\leq 15 \min (92.5 \%)$ were observed in an advanced ambulance (Holm $P=0.029,0.039,0.049$, and 0.019, respectively).

The results indicated the percentage of $\mathrm{RT} \leq 8 \mathrm{~min}$ ranged from 13.1 to $56.6 \%$ across six regions. The highest percentage was found in the north-east, whereas the lowest percentage was found in Bangkok. Operations during 18.00-06.00 achieved RT $\leq 8$ min more than during $06.00-18.00$ (51.2\% versus $47.5 \%$, Holm $P=0.009$ ). Operations by FR had the highest percentage of RT $\leq 8$ min, compared to BLS and ALS teams with $67.3 \%$ versus $53.3 \%$ and $33.9 \%$, respectively (Holm $P=0.039$ ). Operations which were prioritized as emergency level had a lower percentage of RT $\leq 8 \mathrm{~min}$, compared to urgent cases $(38.2 \%$ versus $59.4 \%$, Holm $P=0.029)$. There was a higher percentage of $\mathrm{RT} \leq 8 \mathrm{~min}$ when considering only subjects who were within $10 \mathrm{~km}$ from the ambulance parking, see Table 5.

Figure 1 showed a heat map of the percentage of the subjects who were within $10 \mathrm{~km}$ from the ambulance parking (B), $\mathrm{RT} \leq 8 \mathrm{~min}(\mathrm{C})$, and scene time $\leq 15 \mathrm{~min}$ (D), across 76 provinces and Bangkok. The percentage of the subjects who were within $10 \mathrm{~km}$ in most provinces of the northern, north-eastern, and southern regions were higher than those in the middle, eastern, western regions, and Bangkok, see Fig. 1B. Moreover, most provinces had a low percentage of $\mathrm{RT} \leq 8 \mathrm{~min}$, especially those in the west, the lower part of the middle, the east, and Bangkok, see Fig. 1C. However, all provinces had a high percentage of the scene time $\leq 15 \mathrm{~min}$, except for Bangkok and the vicinity, see Fig. 1D.

\section{Discussion}

Analysis of the national database showed that only half of the suspected stroke patients in Thailand were transported by ALS ambulances. A median total prehospital time was approximately $30 \mathrm{~min}$ which was mainly spent on transportation, response, and scene time. Nevertheless, there was a good performance of dispatch, activation, and scene time, but only half of the operations met the target KPI of RT.

The current recommendation for prehospital management for suspected stroke patients includes an early recognition of signs/symptoms, an immediate activation of 
Table 1 Characteristics of suspected stroke patients who were transported to hospital by ambulance between 2015 and 2018

\begin{tabular}{|c|c|c|c|c|c|c|c|c|c|c|}
\hline \multirow[t]{4}{*}{ Characteristics } & \multirow{2}{*}{\multicolumn{2}{|c|}{ Total }} & \multicolumn{8}{|l|}{ Years } \\
\hline & & & \multicolumn{2}{|l|}{2015} & \multicolumn{2}{|l|}{2016} & \multicolumn{2}{|l|}{2017} & \multicolumn{2}{|l|}{2018} \\
\hline & $n$ & (\%) & $n$ & $(\%)$ & $n$ & $(\%)$ & $n$ & (\%) & $n$ & $(\%)$ \\
\hline & 53,536 & (100) & 9829 & $(100)$ & 11,844 & $(100)$ & 14,456 & $(100)$ & 17,407 & (100) \\
\hline \multicolumn{11}{|l|}{ Regions } \\
\hline North & 4736 & (8.8) & 764 & (7.8) & 1088 & $(9.2)$ & 1306 & (9) & 1578 & $(9.1)$ \\
\hline North-East & 20,831 & (38.9) & 4100 & $(41.7)$ & 4565 & $(38.5)$ & 5645 & (39) & 6521 & $(37.5)$ \\
\hline West & 3587 & $(6.7)$ & 684 & $(7)$ & 815 & $(6.9)$ & 895 & $(6.2)$ & 1193 & $(6.9)$ \\
\hline Middle & 9926 & (18.5) & 1761 & $(17.9)$ & 2085 & $(17.6)$ & 2761 & $(19.1)$ & 3319 & (19.1) \\
\hline East & 3482 & $(6.5)$ & 583 & $(5.9)$ & 776 & $(6.6)$ & 949 & $(6.6)$ & 1174 & $(6.7)$ \\
\hline South & 8072 & (15.1) & 1523 & $(15.5)$ & 1752 & $(14.8)$ & 2140 & $(14.8)$ & 2657 & (15.3) \\
\hline Bangkok & 2902 & (5.4) & 414 & $(4.2)$ & 763 & $(6.4)$ & 760 & (5.3) & 965 & $(5.5)$ \\
\hline \multicolumn{11}{|l|}{ Shift } \\
\hline 06.00-18.00 & 41,476 & (77.5) & 7634 & $(77.7)$ & 9169 & $(77.4)$ & 11,264 & $(77.9)$ & 13,409 & $(77)$ \\
\hline $18.00-06.00$ & 12,060 & (22.5) & 2195 & $(22.3)$ & 2675 & $(22.6)$ & 3192 & $(22.1)$ & 3998 & $(23)$ \\
\hline \multicolumn{11}{|l|}{ Levels } \\
\hline ALS & 26,813 & $(50.1)$ & 4855 & $(49.4)$ & 5910 & $(49.9)$ & 7336 & $(50.7)$ & 8712 & $(50)$ \\
\hline ILS and BLS & 8502 & (15.9) & 1718 & $(17.5)$ & 1877 & $(15.8)$ & 2135 & $(14.8)$ & 2772 & (15.9) \\
\hline$F R$ & 18,221 & (34) & 3256 & $(33.1)$ & 4057 & $(34.3)$ & 4985 & $(34.5)$ & 5923 & (34) \\
\hline \multicolumn{11}{|l|}{ Dispatch triage } \\
\hline Emergency & 27,940 & $(52.2)$ & 5041 & $(51.3)$ & 6157 & $(52)$ & 7641 & $(52.9)$ & 9101 & $(52.3)$ \\
\hline Urgency & 25,596 & $(47.8)$ & 4788 & $(48.7)$ & 5687 & $(48)$ & 6815 & $(47.1)$ & 8306 & $(47.7)$ \\
\hline Distance (km), median (IQR) & 5 & $(2,9)$ & 5 & $(2,9)$ & 5 & $(2,9)$ & 5 & $(2,9)$ & 5 & $(2,9)$ \\
\hline$\leq 10 \mathrm{~km}$ & 42,921 & $(80.2)$ & 7893 & $(80.3)$ & 9563 & $(80.7)$ & 11,541 & $(79.8)$ & 13,924 & $(80)$ \\
\hline$>10 \mathrm{~km}$ & 10,615 & (19.8) & 1936 & $(19.7)$ & 2281 & $(19.3)$ & 2915 & $(20.2)$ & 3483 & $(20)$ \\
\hline \multicolumn{11}{|l|}{ Dispatch time } \\
\hline$>1 \min$ & 4417 & (8.3) & 726 & $(7.4)$ & 1018 & (8.6) & 1131 & $(7.8)$ & 1542 & $(8.9)$ \\
\hline$\leq 1 \min$ & 49,119 & $(91.7)$ & 9103 & $(92.6)$ & 10,826 & $(91.4)$ & 13,325 & $(92.2)$ & 15865 & $(91.1)$ \\
\hline \multicolumn{11}{|l|}{ Activation time } \\
\hline$>2 \min$ & 6262 & $(11.7)$ & 1038 & $(10.6)$ & 1368 & $(11.6)$ & 1698 & $(11.7)$ & 2158 & (12.4) \\
\hline$\leq 2 \min$ & 47,274 & (88.3) & 8791 & $(89.4)$ & 10,476 & $(88.4)$ & 12,758 & $(88.3)$ & 15,249 & (87.6) \\
\hline \multicolumn{11}{|l|}{ Response time } \\
\hline$>8 \min$ & 27,661 & $(51.7)$ & 4900 & $(49.9)$ & 6009 & $(50.7)$ & 7578 & $(52.4)$ & 9174 & (52.7) \\
\hline$\leq 8 \min$ & 25,875 & $(48.3)$ & 4929 & $(50.1)$ & 5835 & $(49.3)$ & 6878 & $(47.6)$ & 8233 & $(47.3)$ \\
\hline \multicolumn{11}{|l|}{ Scene time } \\
\hline$>15 \min$ & 2682 & (5.0) & 419 & $(4.3)$ & 646 & $(5.5)$ & 732 & $(5.1)$ & 885 & $(5.1)$ \\
\hline$\leq 15 \min$ & 50,854 & $(95.0)$ & 9410 & $(95.7)$ & 11,198 & $(94.5)$ & 13,724 & $(94.9)$ & 16,522 & (94.9) \\
\hline
\end{tabular}

$A L S$ advanced life support, $B L S$ basic life support, $F R$ first responder, ILS intermediate life support, IQR interquartile range

EMS system, a response with high level EMS ambulance, an application of prehospital stroke screening tools and rapid transport of the patients to stroke centers [3, 2528]. Several important findings were found:

First, only half of the suspected stroke subjects who called the EMS system were prioritized as emergency level (52.5\%), and transported to the receiving hospitals by ALS ambulances (50.1\%). The percentage was much lower than that in the previous studies in the developed countries which were 60 to $89 \%$ [29-31]. These findings could be explained by the fact that the stroke fast track protocol is not implemented on EMS system. Suspected stroke patients are not immediately prioritized to be high level of triage but they are mainly prioritized based on life-saving conditions, e.g., alteration of consciousness or breathing problems. In addition, there might be 
Table 2 Number of subjects who were far from parking $\leq 10 \mathrm{~km}$ versus $>10 \mathrm{~km}$

\begin{tabular}{|c|c|c|c|c|c|c|c|}
\hline \multirow[t]{2}{*}{ Factors } & \multirow[t]{2}{*}{$N$} & \multicolumn{2}{|l|}{$\leq 10 \mathrm{~km}$} & \multicolumn{2}{|l|}{$>10 \mathrm{~km}$} & \multirow{2}{*}{$\begin{array}{l}P \\
\text { value }\end{array}$} & \multirow{2}{*}{$\begin{array}{l}\text { Holm } \\
P \\
\text { value }\end{array}$} \\
\hline & & $n$ & (\%) & $\bar{n}$ & (\%) & & \\
\hline \multicolumn{8}{|l|}{ Regions } \\
\hline North & 4736 & 3827.00 & (80.8) & 909 & $(19.2)$ & $<0.001$ & 0.020 \\
\hline North-East & 20,831 & $17,291.00$ & (83) & 3540.00 & (17) & & \\
\hline West & 3587 & 2820.00 & (78.6) & 767 & $(21.4)$ & & \\
\hline Middle & 9926 & 7778.00 & (78.4) & 2148.00 & (21.6) & & \\
\hline East & 3482 & 2439.00 & (70) & 1043.00 & (30) & & \\
\hline South & 8072 & 6841.00 & $(84.7)$ & 1231.00 & (15.3) & & \\
\hline Bangkok & 2902 & 1925.00 & (66.3) & 977 & (33.7) & & \\
\hline \multicolumn{8}{|l|}{ Shifts } \\
\hline 06.00-18.00 & 41,476 & $32,908.00$ & (79.3) & 8568.00 & (20.7) & $<0.001$ & 0.009 \\
\hline $18.00-06.00$ & 12,060 & $10,013.00$ & (83) & 2047.00 & (17) & & \\
\hline \multicolumn{8}{|l|}{ Levels } \\
\hline ALS & 26,813 & $19,395.00$ & (72.3) & 7418.00 & $(27.7)$ & $<0.001$ & 0.039 \\
\hline ILS and BLS & 8502 & 7053.00 & (83) & 1449.00 & (17) & & \\
\hline$F R$ & 18,221 & $16,473.00$ & (90.4) & 1748.00 & (9.6) & & \\
\hline \multicolumn{8}{|l|}{ Dispatch triage } \\
\hline Emergency & 27,940 & $20,846.00$ & (74.6) & 7094.00 & (25.4) & $<0.001$ & 0.029 \\
\hline Urgency & 25,596 & $22,075.00$ & (86.2) & 3521.00 & (13.8) & & \\
\hline
\end{tabular}

$A L S$ advanced life support, $B L S$ basic life support; $F R$ first responder, ILS intermediate life support

limited numbers and distributions of ALS ambulances across Thailand. As a result, lower level ambulances are deployed instead.

Second, we found a huge gap between the proportion of emergency level of phone triage and the proportion of ALS ambulances serving suspected stroke patients among different regions despite a widespread use of emergency medical triage and criteria-based protocols. This problem suggests that the mentioned protocols might not be effectively implemented.
Third, there were a higher number of patients transported to hospitals in day time, compared to night time. This might be explained by the symptoms of stroke that could be detected while the patients have full consciousness. In general, most of the patients observe the abnormalities after waking up or during the daytime and subsequently call for help.

According to the mentioned findings, assigning suspected stroke patients as a high level of triage is important and should be emphasized in stroke fast tract protocol. Besides, regular triage audits should be

Table 3 Characteristics of EMS operation based on regions

\begin{tabular}{|c|c|c|c|c|c|c|c|c|c|}
\hline \multirow[t]{2}{*}{ Characteristics } & \multicolumn{7}{|l|}{ Regions } & \multirow{2}{*}{$\begin{array}{l}P \\
\text { value }\end{array}$} & \multirow{2}{*}{$\begin{array}{l}\text { Holm } \\
P \\
\text { value }\end{array}$} \\
\hline & $\begin{array}{l}\text { North } \\
n(\%)\end{array}$ & $\begin{array}{l}\text { North-East } \\
n(\%)\end{array}$ & $\begin{array}{l}\text { West } \\
n(\%)\end{array}$ & $\begin{array}{l}\text { Middle } \\
n(\%)\end{array}$ & $\begin{array}{l}\text { East } \\
n(\%)\end{array}$ & $\begin{array}{l}\text { South } \\
n(\%)\end{array}$ & $\begin{array}{l}\text { Bangkok } \\
n(\%)\end{array}$ & & \\
\hline \multicolumn{10}{|l|}{ Phone triage } \\
\hline Emergency & $2126(55.6)$ & 5759 (33.3) & $1347(47.8)$ & $5266(67.7)$ & 1436 (58.9) & $3273(47.8)$ & $1639(85.1)$ & $<0.001$ & 0.009 \\
\hline Urgency & 1701 (44.4) & $11,532(66.7)$ & $1473(52.2)$ & $2512(32.3)$ & 1003 (41.1) & $3568(52.2)$ & $286(14.9)$ & & \\
\hline \multicolumn{10}{|l|}{ Levels } \\
\hline ALS & 1883 (49.2) & $5204(30.1)$ & $1520(53.9)$ & $5085(65.4)$ & 1411 (57.9) & $2674(39.1)$ & $1618(84.1)$ & $<0.001$ & 0.019 \\
\hline ILS and BLS & $642(16.8)$ & $2733(15.8)$ & $657(23.3)$ & 1038 (13.3) & $94(3.9)$ & $1582(23.1)$ & $307(15.9)$ & & \\
\hline FR & 1302 (34) & $9354(54.1)$ & $643(22.8)$ & 1655 (21.3) & 934 (38.3) & 2585 (37.8) & 0 & & \\
\hline
\end{tabular}


Table 4 EMS operations times among suspected stroke patients based on levels of ambulance

\begin{tabular}{|c|c|c|c|c|c|c|}
\hline \multirow[t]{2}{*}{ Times } & Overall & \multicolumn{4}{|c|}{ Levels of ambulance, median (IQR) } & \multirow[t]{2}{*}{ Holm $P$ value } \\
\hline & median (IQR) & FR & ILS/BLS & Advance & $P$ value & \\
\hline Dispatch time & $1(1,1)$ & $1(1,1)$ & $1(1,1)$ & $1(1,1)$ & $<0.001$ & 0.005 \\
\hline Activation time & $1(1,2)$ & $1(1,1)$ & $1(0,1)$ & $1(1,2)$ & $<0.001$ & 0.010 \\
\hline Response time & $9(5,14)$ & $6(4,10)$ & $8(5,13)$ & $11(7,17)$ & $<0.001$ & 0.029 \\
\hline Scene time & $5(2,8)$ & $3(2,5)$ & $4(2,7)$ & $5(3,10)$ & $<0.001$ & 0.024 \\
\hline Transportation time & $10(6,17)$ & $14(8,21)$ & $10(5,15)$ & $9(5,14)$ & $<0.001$ & 0.019 \\
\hline Total prehospital time & $29(21,39)$ & $28(20,37)$ & $27(19,36)$ & $30(21,42)$ & $<0.001$ & 0.014 \\
\hline \multirow[t]{2}{*}{ Times } & Overall & \multicolumn{4}{|c|}{ Levels of ambulance, $n(\%)$} & Holm $P$ value \\
\hline & $n(\%)$ & FR & ILS/BLS & Advance & $P$ value & \\
\hline \multicolumn{7}{|l|}{ Dispatch time } \\
\hline$>1 \min$ & $4417(8.3)$ & $768(4.2)$ & $636(7.5)$ & $3013(11.2)$ & $<0.001$ & 0.029 \\
\hline$\leq 1 \mathrm{~min}$ & $49,119(91.7)$ & $17,453(95.8)$ & 7866 (92.5) & $23,800(88.8)$ & & \\
\hline \multicolumn{7}{|l|}{ Activation time } \\
\hline$>2 \min$ & $6262(11.7)$ & $1240(6.8)$ & $595(7)$ & $4427(16.5)$ & $<0.001$ & 0.039 \\
\hline$\leq 2 \mathrm{~min}$ & $47,274(88.3)$ & $16,981(93.2)$ & 7907 (93) & $22,386(83.5)$ & & \\
\hline \multicolumn{7}{|l|}{ Response time } \\
\hline$>8 \mathrm{~min}$ & $27,661(51.7)$ & 5967 (32.7) & 3975 (46.8) & $17,719(66.1)$ & $<0.001$ & 0.049 \\
\hline$\leq 8 \mathrm{~min}$ & $25,875(48.3)$ & $12,254(67.3)$ & $4527(53.2)$ & 9094 (33.9) & & \\
\hline \multicolumn{7}{|l|}{ Scene time } \\
\hline$>15 \min$ & $2682(5)$ & $378(2.1)$ & $291(3.4)$ & $2013(7.5)$ & $<0.001$ & 0.019 \\
\hline$\leq 15 \mathrm{~min}$ & $50,854(95)$ & $17,843(97.9)$ & 8211 (96.6) & $24,800(92.5)$ & & \\
\hline
\end{tabular}

$A L S$ advanced life support, $B L S$ basic life support, $F R$ first responder, ILS intermediate life support

conducted aiming to explore and sustain the standardization of triage protocol used among EMS personnel. In addition, a number of patients could be used to determine an efficient allocation of staff. However, training EMT and FR to assess stroke signs/symptoms under the supervision of standardized direct medical command via tele-consultation might be an area for improvement if increasing the number of ALS ambulances is difficult.

The results showed median total prehospital time was approximately $30 \mathrm{~min}$ which correlated with the previous studies [29-35]. Our results also revealed a high percentage of dispatch $\leq 1 \mathrm{~min}$ and activation $\leq 2 \mathrm{~min}$ $[23,25]$. However, our median RT was longer than that in the recommendation and other studies [3, 25, 27, 29$32,34]$, and only half of the subjects experienced RT $\leq 8$ min. Nonetheless, short dispatch and activation time pointed out that prompt ambulances were available, but long RT also indicated that ambulances took a long time to reach patients. This might be the result of long distance from the ambulance parking to the scene (Tables 1 and 2), traffic, and geographical problems, e.g., mountainous or rural areas.

Advanced ambulances had the lowest percentage of $\mathrm{RT} \leq 8 \mathrm{~min}$, compared to lower level ambulances. This might be explained by different deployment models between ALS versus FR/BLS ambulances in Thailand. ALS ambulances are parked at hospitals as a fixed deployment model, while FR/BLS ambulances are available in the most frequent scene areas as a fluid deployment model. For this reason, the FR/BLS could reach the patients faster but spend longer time transporting patients to hospitals. Therefore, exploring patient distribution in each geographical area and strengthening the collaboration between FR/BLS and advanced ambulances might be required to improve the reallocation of EMS service for stroke patients. Furthermore, redesigning a coordinated system between FR/BLS and ALS ambulances to provide stroke care may be suitable for Thailand's context.

Most of the total prehospital time was spent on traveling from parking to the scene and from the scene to hospital, which differed from that in the previous studies in developed countries where most of the prehospital time is spent at the scene [30, 31, 34]. EMS system in Thailand is a scoop and run model in which patients are initially evaluated and provided with necessary medical treatments at the scene, before being transported to the nearest hospital. Most interventions for stroke protocol (e.g., EKG, intravenous assessment, and blood collection) 
Table 5 Number of RT $\leq 8$ min among overall and subjects in $10 \mathrm{~km}$ from parking

\begin{tabular}{|c|c|c|c|c|c|c|c|c|c|c|c|c|c|c|}
\hline \multirow[t]{3}{*}{ Factors } & \multicolumn{5}{|c|}{ Overall $(N=53,536)$} & \multirow{3}{*}{$\begin{array}{l}P \\
\text { value }\end{array}$} & \multirow{3}{*}{$\begin{array}{l}\text { Holm } \\
\mathrm{P} \\
\text { value }\end{array}$} & \multicolumn{5}{|c|}{$\leq 10 \mathrm{~km}$ distance $(N=42,921)$} & \multirow{3}{*}{$\begin{array}{l}P \\
\text { value }\end{array}$} & \multirow{3}{*}{$\begin{array}{l}\text { Holm } \\
P \\
\text { value }\end{array}$} \\
\hline & \multirow[t]{2}{*}{ Total } & \multicolumn{2}{|c|}{$\leq 8 \mathrm{~min}$} & \multicolumn{2}{|c|}{$>8 \min$} & & & \multirow[t]{2}{*}{ Total } & \multicolumn{2}{|c|}{$\leq 8 \mathrm{~min}$} & \multicolumn{2}{|c|}{$>8 \min$} & & \\
\hline & & $n$ & $\%$ & $n$ & $\%$ & & & & $n$ & $\%$ & $n$ & $\%$ & & \\
\hline \multicolumn{15}{|l|}{ Region } \\
\hline North & 4736 & 2172 & $(45.9)$ & 2564 & $(54.1)$ & $<0.001$ & 0.019 & 3827 & 2134 & $(55.8)$ & 1693 & $(44.2)$ & $<0.001$ & 0.039 \\
\hline North-East & 20,831 & 11,799 & $(56.6)$ & 9032 & $(43.4)$ & & & 17,291 & 11,606 & $(67.1)$ & 5685 & (32.9) & & \\
\hline West & 3587 & 1654 & $(46.1)$ & 1933 & $(53.9)$ & & & 2820 & 1624 & $(57.6)$ & 1196 & $(42.4)$ & & \\
\hline Middle & 9926 & 4000 & $(40.3)$ & 5926 & $(59.7)$ & & & 7778 & 3927 & $(50.5)$ & 3851 & $(49.5)$ & & \\
\hline East & 3482 & 1270 & (36.5) & 2212 & (63.5) & & & 2439 & 1234 & $(50.6)$ & 1205 & $(49.4)$ & & \\
\hline South & 8072 & 4601 & (57) & 3471 & (43) & & & 6841 & 4519 & $(66.1)$ & 2322 & (33.9) & & \\
\hline Bangkok & 2902 & 379 & $(13.1)$ & 2523 & (86.9) & & & 1925 & 331 & $(17.2)$ & 1594 & $(82.8)$ & & \\
\hline \multicolumn{15}{|l|}{ Shifts } \\
\hline 06.00-18.00 & 41,476 & 19,696 & $(47.5)$ & 21,780 & $(52.5)$ & $<0.001$ & 0.009 & 32,908 & 19,300 & (58.6) & 13,608 & (41.4) & $<0.001$ & 0.029 \\
\hline $18.00-06.00$ & 12,060 & 6179 & $(51.2)$ & 5881 & $(48.8)$ & & & 10,013 & 6075 & $(60.7)$ & 3938 & (39.3) & & \\
\hline \multicolumn{15}{|l|}{ Levels } \\
\hline ALS & 26,813 & 9094 & (33.9) & 17,719 & $(66.1)$ & $<0.001$ & 0.039 & 19,395 & 8859 & $(45.7)$ & 10,536 & (54.3) & $<0.001$ & 0.019 \\
\hline BLS & 8502 & 4527 & $(53.2)$ & 3975 & $(46.8)$ & & & 7053 & 4446 & (63) & 2607 & (37) & & \\
\hline FR & 18,221 & 12,254 & (67.3) & 5967 & (32.7) & & & 16,473 & 12,070 & (73.3) & 4403 & $(26.7)$ & & \\
\hline \multicolumn{15}{|l|}{ Dispatch triage } \\
\hline Emergency & 27,940 & 10,667 & $(38.2)$ & 17,273 & $(61.8)$ & $<0.001$ & 0.029 & 20,846 & 10,399 & $(49.9)$ & 10,447 & $(50.1)$ & $<0.001$ & 0.009 \\
\hline Urgency & 25,596 & 15,208 & $(59.4)$ & 10,388 & $(40.6)$ & & & 22,075 & 14,976 & (67.8) & 7099 & $(32.2)$ & & \\
\hline
\end{tabular}

$A L S$ advanced life support, $B L S$ basic life support, $F R$ first responder, ILS intermediate life support

are primarily performed at ED. Therefore, our scene time was very short. From this, implementing stroke screening by EMS personnel and activating stroke fast track team before the patients arrive at ED might be the options to improve stroke chain of survival [3, 25-27].

In Bangkok, $85 \%$ of the cases was transported by ALS ambulances which was very high, compared to other regions. This might be because FR ambulances are not available. Thus, ALS ambulances are activated in high proportion. There are a large number of both public and private hospitals in Bangkok, compared to the upcountry. Nevertheless, the uneven hospital distribution and the complexity of the capital city (e.g., dense population, houses, or traffic jams) could explain why only $13 \%$ of the operations had $\mathrm{RT} \leq 8 \mathrm{~min}$.

The strength of this study was that we used the national database which represents all EMS operations across Thailand. In addition, this data set contains a low amount of missing time information and this decreased selection bias. However, some limitations were also identified. First, this database includes only prehospital information. As a result, we were unable to assess other clinical important factors (e.g., facilities of the receiving hospitals and patients' final diagnosis and outcomes). For this reason, the development of prehospital stroke care should include a comprehensive database linked from prehospital to hospital phases. Second, we were unable to estimate the proportion of patients self-transporting to the hospital because we included only the subjects who were transported by the ambulance. Although this proportion was not estimated, previous studies reported less than $20 \%$ of Thai stroke patients visiting ED by EMS system [16-19]. Therefore, an emphasis on people's education about stroke recognition and an access to EMS service should be included into the protocol.

Based on our results, several strategies should be considered for implementing prehospital stroke care in Thailand as follows:

1. People should be educated about early stroke recognition (e.g., signs or symptoms of stroke) and an access to EMS service. These will boost an early recognition and immediate activation of EMS system.

2. Phone triage protocol should be revised by increasing the level of triage among suspected stroke patients and responding with a high level of ambulance.

3. EMS personnel should be empowered and trained with prehospital stroke screening tools which aim to transport the right patient to the right receiving hospital.

4. The coordination system between FR, BLS, and ALS ambulances in taking care of stroke patients 
and taking direct medical command via teleconsultation might be appropriate for Thailand, where an increase in ALS units is difficult.

5. A comprehensive and reliable stroke registry system linking from prehospital to hospital phase should be developed. This will help the system to determine several dimensions of stroke care, e.g., time interval, appropriateness of prehospital/in hospital treatment, appropriateness of the receiving hospitals, a final diagnosis, and patient outcomes. Finally, regular system audits should be conducted to monitor and improve stroke care.

\section{Conclusions}

In summary, this study demonstrated that prehospital time from the receiving EMS call to the patient's arrival at ER was approximately $30 \mathrm{~min}$. This time interval was mainly spent on traveling from the ambulance parking to the scene and transporting patients from the scene to ER. Only $48 \%$ of the total operations had RT $\leq 8 \mathrm{~min}$, but most of them (95\%) had the scene time $\leq 15 \mathrm{~min}$.

\section{Abbreviations}

ALS: Advanced life support; BLS: Basic life support; ED: Emergency department; EMS: Emergency medical service; EMT: Emergency medical technician; FR: First responder; ILS: Intermediate life support; IQR: Interquartile range; KPI: Key performance indicator; RT: Response time

\section{Supplementary Information}

The online version contains supplementary material available at https://doi. org/10.1186/s12245-021-00361-w.

Additional file 1:. 25 chief complaints of emergency medical triage protocol and criteria-based dispatch 2013.

\section{Acknowledgements}

None.

\section{Authors' contributions}

PT and PA conceived the study concept and designed methods. PT and PA carried out acquisition of the data and performed the statistical analysis. PT PA, AW, and NM interpreted the data and drafted the manuscript. The authors read and approved the final manuscript.

\section{Funding}

None.

\section{Availability of data and materials}

The datasets and/or analyzed during the current study are available from the corresponding author on reasonable request.

\section{Declarations}

Ethics approval and consent to participate

This study was approved by the Ethic Committee of Faculty of Medicine Ramathibodi Hospital, Mahidol University, Thailand, with a waiving of informed consent.

\section{Consent for publication}

Not applicable

\section{Competing interests}

The authors declare that they have no competing interests.

\section{Author details}

${ }^{1}$ Chakri Naruebodindra Medical Institute, Faculty of Medicine Ramathibodi Hospital, Mahidol University, Samut Prakan 10540, Thailand. ${ }^{2}$ Department of Emergency Medicine, Faculty of Medicine Ramathibodi Hospital, Mahidol University, Bangkok, Thailand.

Received: 5 November 2020 Accepted: 6 June 2021

Published online: 19 July 2021

\section{References}

1. Donkor ES. Stroke in the 21(st) century: a snapshot of the burden, epidemiology, and quality of life. Stroke Res Treat. 2018;2018:3238165. https://doi.org/10.1155/2018/3238165 eCollection 2018.

2. Kim AS, Cahill E, Cheng NT. Global stroke belt: geographic variation in stroke burden worldwide. Stroke. 2015;46(12):3564-70. https://doi.org/10.11 61/STROKEAHA.115.008226 Epub 2015 Oct 20.

3. Powers WJ, Rabinstein AA, Ackerson T, Adeoye OM, Bambakidis NC, Becker K, et al. 2018 Guidelines for the early management of patients with acute ischemic stroke: a guideline for healthcare professionals from the American Heart Association/American Stroke Association. Stroke. 2018;49(3):e46-e110. https://doi.org/10.1161/STR.0000000000000158 Epub 2018 Jan 24.

4. Kessler C, Khaw AV, Nabavi DG, Glahn J, Grond M, Busse O. Standardized prehospital treatment of stroke. Dtsch Arztebl Int. 2011;108(36):585-91. https://doi.org/10.3238/arztebl.2011.0585 Epub 2011 Sep 9.

5. Binning MJ, Sanfillippo G, Rosen W, D'ambrosio M, Veznedaroglu $E_{\text {, }}$ Liebman $\mathrm{K}$, et al. The neurological emergency room and prehospital stroke alert: the whole is greater than the sum of its parts. Neurosurgery. 2014; 74(3):281-5; discussion 5. https://doi.org/10.1227/NEU.0000000000000259.

6. Madhok DY, Keenan KJ, Cole SB, Martin C, Hemphill JC 3rd. Prehospital and emergency department-focused mission protocol improves thrombolysis metrics for suspected acute stroke patients. J Stroke Cerebrovasc Dis. 2019;28(12):104423. https:/doi.org/10.1016/j.jstrokecerebrovasdis.2019 Epub 2019 Oct 9.

7. Olascoaga Arrate A, Freijo Guerrero MM, Fernández Maiztegi C, Azkune Calle I, Silvariño Fernández R, Fernández Rodríguez M, et al. Use of emergency medical transport and impact on time to care in patients with ischaemic stroke. Neurologia. 2019;34(2):80-8. https://doi.org/10.1016/j.nrl.2016.11.004 Epub 7 Jan 13.

8. Acker J, Pancioli A, Crocco T, Eckstein M, Jauch E, Larrabee H, et al. Implementation strategies for emergency medical services within stroke systems of care: a policy statement from the American Heart Association/ American Stroke Association Expert Panel on Emergency Medical Services Systems and the Stroke Council. Stroke. 2007;38:3097-115.

9. Jauch E, Saver J, Adams H, Bruno A, Connors J, Demaerschalk B, et al. Guidelines for the early management of patients with acute ischemic stroke: a guideline for healthcare professionals from the American Heart Association/American Stroke Association. Stroke. 2013:44(3):870-947.

10. Centers for Disease Control and Prevention (CDC). Prehospital and hospital delays after stroke onset--United States, 2005-2006. MMWR Morb Mortal Wkly Rep. 2007;56(19):474-8.

11. Lau KK, Yu EL, Lee MF, Ho SH, Ng PM, Leung CS. Ambulance use affects timely emergency treatment of acute ischaemic stroke. Hong Kong Med J. 2018;24(4):335-9. https://doi.org/10.12809/hkmj177025. Epub 2018 Jul 30.

12. Minnerup J, Wersching $H$, Unrath M, Berger K. Effects of emergency medical service transport on acute stroke care. Eur J Neurol. 2014;21(10):1344-7. https://doi.org/10.1111/ene.12367 Epub 2014 Jan 28.

13. Kongbunkiat K, Kasemsap N, Thepsuthammarat K, Tiamkao S, Sawanyawisuth K. National data on stroke outcomes in Thailand. J Clin Neurosci. 2015;22(3): 493-7. https://doi.org/10.1016/j.jocn.2014.08.031 Epub 5 Jan 13.

14. Hanchaiphiboolkul S, Poungvarin N, Nidhinandana S, Suwanwela NC, Puthkhao P, Towanabut $S$, et al. Prevalence of stroke and stroke risk factors in Thailand: Thai Epidemiologic Stroke (TES) Study. J Med Assoc Thail. 2011; 94(4):427-36.

15. Bundhamcharoen $K$, Odton P, Phulkerd S, Tangcharoensathien V. Burden of disease in Thailand: changes in health gap between 1999 and 2004. BMC Public Health. 2011;11:53. https://doi.org/10.1186/471-2458-11-53.

16. Bodeepat W, Chatchadaporn O. Development of stroke fast track management in emergency department, Nakhonpathom Hospital. Region 4-5 Med J. 2017;36(4):251-63.

17. Metta S, Malai S, Jirasuk L, Tuenchai S, Supasin D. Time to access and referral of stroke patients in Thakhuntho Hospital, Thakhuntho District, Kalasin Province. Hahasarakham Hosp J. 2020;17(3):140-7. 
18. Muengtaweepongsa S, Hunghok W, Harnirattisai T. Poor recognition of prompted treatment seeking even with good knowledge of stroke warning signs contribute to delayed arrival of acute ischemic stroke patients in Thailand. J Stroke Cerebrovasc Dis. 2014;23(5):948-52. https://doi.org/10.101 6/j.jstrokecerebrovasdis.2013.07.044 Epub Oct 15.

19. Wongwiangjunt S, Komoltri C, Poungvarin N, Nilanont Y. Stroke awareness and factors influencing hospital arrival time: a prospective observational study. J Med Assoc Thail. 2015;98(3):260-4.

20. Ministry of Interior. In: Report of population and house statistics Year 2019. Ministry of Interior. 2020. https://stat.bora.dopa.go.th/stat/statnew/statTDD/ views/showProvinceData.php. Accessed 24 Dec 2019

21. Office of the Royal Society. In: Regional division of Thailand. Office of the Royal Society. 2020. http://www.royin.go.th. Accessed 24 Dec 2019.

22. National institute for emergency medicine. Emergency medical triage protocol and criteria basd dispatch. 2nd ed. Bangkok: Ministry of Public Health; 2013.

23. National Institute for Emergency Medicine. Annual report 2015. Bangkok: Ministry of Public Health; 2013.

24. Holm S. A simple sequentially rejective multiple test procedure. Scand J Stat. 1979;6(2):65-70.

25. Glober NK, Sporer KA, Guluma KZ, Serra JP, Barger JA, Brown JF, et al. Acute stroke: current evidence-based recommendations for prehospital care. West J Emerg Med. 2016;17(2):104-28. https://doi.org/10.5811/westjem.2015.12.2 8995 Epub 2016 Mar 02.

26. Kim DH, Kim B, Jung C, Nam HS, Lee JS, Kim JW, et al. Consensus statements by Korean Society of Interventional Neuroradiology and Korean Stroke Society: hyperacute endovascular treatment workflow to reduce door-to-reperfusion time. J Korean Med Sci. 2018;33(19):e143. https://doi. org/10.3346/jkms.2018.33.e143 eCollection May 7.

27. Kircher C, Kreitzer N, Adeoye O. Pre and intrahospital workflow for acute stroke treatment. Curr Opin Neurol. 2016;29(1):14-9. https://doi.org/10.1097/ WCO.0000000000000281

28. Berglund A, von Euler M, Schenck-Gustafsson K, Castrén M, Bohm K Identification of stroke during the emergency call: a descriptive study of callers' presentation of stroke. BMJ Open. 2015;5(4):e007661. https://doi. org/10.1136/bmjopen-2015-.

29. Brown AT, Wei F, Culp WC, Brown G, Tyler R, Balamurugan A, et a . Emergency transport of stroke suspects in a rural state: opportunities for improvement论访， . Am J Emerg Med. 2016;34(8):1640-4. https://doi.org/1 0.1016/j.ajem.2016.06.044 Epub 2016 Jun 14.

30. Golden AP, Odoi A. Emergency medical services transport delays for suspected stroke and myocardial infarction patients. BMC Emerg Med. 2015; 15. https://doi.org/10.1186/s12873-015-0060-3.

31. Puolakka T, Strbian D, Harve H, Kuisma M, Lindsberg PJ. Prehospital phase of the stroke chain of survival: a prospective observational study. J Am Heart Assoc. 2016;5(5). https://doi.org/10.1161/JAHA.115.002808.

32. Patel MD, Brice JH, Moss C, Suchindran CM, Evenson KR, Rose KM, et al. An evaluation of emergency medical services stroke protocols and scene times. Prehosp Emerg Care. 2014;18(1):15-21. Epub 2013 Sep 12. https://doi.org/1 0.3109/10903127.2013.825354.

33. Drenck N, Viereck S, Bækgaard JS, Christensen KB, Lippert F, Folke F. Prehospital management of acute stroke patients eligible for thrombolysis - an evaluation of ambulance on-scene time. Scand J Trauma Resusc Emerg Med. 2019;27. https://doi.org/10.1186/s13049-018-0580-4.

34. Simonsen SA, Andresen M, Michelsen L, Viereck S, Lippert FK, Iversen HK Evaluation of pre-hospital transport time of stroke patients to thrombolytic treatment. Scand J Trauma Resusc Emerg Med. 2014;22. https://doi.org/1 0.1186/s13049-014-0065-z.

35. Ohwaki K, Watanabe T, Shinohara T, Nakagomi T, Yano E. Relationship between time from ambulance call to arrival at emergency center and level of consciousness at admission in severe stroke patients. Prehosp Disaster Med. 2013;28(1):39-42. https://doi.org/10.1017/S1049023X12001549 Epub 2012 Oct 23.

\section{Publisher's Note}

Springer Nature remains neutral with regard to jurisdictional claims in published maps and institutional affiliations.

Ready to submit your research? Choose BMC and benefit from:

- fast, convenient online submission

- thorough peer review by experienced researchers in your field

- rapid publication on acceptance

- support for research data, including large and complex data types

- gold Open Access which fosters wider collaboration and increased citations

- maximum visibility for your research: over $100 \mathrm{M}$ website views per year

At BMC, research is always in progress.

Learn more biomedcentral.com/submissions 